\title{
Strategic logistics outsourcing: An integrated QFD and fuzzy AHP approach
}

\author{
William $\mathrm{Ho}^{1, *}$, Ting $\mathrm{He}^{2}$, Carman Ka Man Lee ${ }^{3}$, Ali Emrouznejad ${ }^{1}$ \\ ${ }^{1}$ Operations and Information Management Group \\ Aston Business School, Aston University \\ Birmingham B4 7ET, United Kingdom \\ ${ }^{2}$ Research Centre of Intelligent Computing for Enterprises and Services \\ School of Computer Science and Technology, Harbin Institute of Technology \\ Harbin, P.R.China 150001 \\ ${ }^{3}$ Division of Systems and Engineering Management \\ School of Mechanical and Aerospace Engineering \\ Nanyang Technological University \\ 50 Nanyang Avenue, Singapore 639798 \\ *E-mail: w.ho@aston.ac.uk; Tel: +44 (0)121 2043342
}

\begin{abstract}
This paper develops an integrated approach, combining quality function deployment (QFD), fuzzy set theory, and analytic hierarchy process (AHP) approach, to evaluate and select the optimal third-party logistics service providers (3PLs). In the approach, multiple evaluating criteria are derived from the requirements of company stakeholders using a series of house of quality (HOQ). The importance of evaluating criteria is prioritized with respect to the degree of achieving the stakeholder requirements using fuzzy AHP. Based on the ranked criteria, alternative 3PLs are evaluated and compared with each other using fuzzy AHP again to make an optimal selection. The effectiveness of proposed approach is demonstrated by applying it to a Hong Kong based enterprise that supplies hard disk components. The proposed integrated approach outperforms the existing approaches because the outsourcing strategy and 3PLs selection are derived from the corporate/business strategy.
\end{abstract}

Keywords: Logistics outsourcing, third-party logistics service providers, selection, quality function deployment, analytic hierarchy process, fuzzy

*Corresponding author 


\section{Introduction}

Logistics outsourcing or third-party logistics is regarded as using external companies to perform some or all logistics functions, including transportation, distribution, warehousing, inventory management, order processing, and material handling, that have traditionally been performed within an outsourcing firm (Sink and Langley, 1997; Razzaque and Sheng, 1998; Işıklar et al., 2007). Those logistics functions can be treated as non value-added activities because they are critical to the smooth running of the business, but not a unique ingredient of the overall product (Sink and Langley, 1997). Because of this reason, firms tend to outsource those activities to the external companies or 3PLs, and focus on value-added activities to develop sustainable competitive advantage.

Evaluation and selection of 3PL is a critical step in the logistics outsourcing process because an appropriate 3PL will help the outsourcing firms to reduce capital investment in facilities, equipment, information technology and manpower, increase the flexibility of outsourcing firms in adapting to changes in the market, reduce inventory and improve inventory turnover rate, improve on-time delivery, reduce the transportation cost, and so on (Razzaque and Sheng, 1998; Liu and Wang, 2009).

Choosing the right 3PLs involves much more than scanning a series of price list, and choices will depend on a wide range of factors which involve both quantitative and qualitative. Various individual and integrated multi-criteria decision making approaches have been proposed for the 3PL selection, such as AHP, analytic network process (ANP), artificial neural networks (ANN), case-based reasoning (CBR), data envelopment analysis (DEA), rule-based reasoning (RBR), technique for order preference by similarity to ideal solution (TOPSIS), and so on. Although these approaches can deal with multiple and conflicting criteria, they have not taken into consideration the impact of business objectives and requirements of company stakeholders on the evaluating criteria. In reality, the weightings of 3PL evaluating criteria depend a lot on business priorities and strategies. In cases where the weightings are assigned arbitrarily and subjectively without considering the "voice" of company stakeholders, the selected 3PL cannot provide what the company exactly wants.

To enable the "voice" of company stakeholders is considered, this paper develops an integrated approach, combining QFD, fuzzy set theory, and AHP, for selecting 3PL strategically. HOQ, a technique of QFD, is responsible for translating the requirements of company stakeholders into evaluating criteria. Since multiple evaluating criteria are proposed, and some of them are qualitative and uncertain, the fuzzy set theory is therefore incorporated into the traditional AHP to enable company stakeholders to express their linguistic 
preferences, and to transform those preferences into the quantitative form for comparison. Fuzzy AHP is responsible for the assignment of importance ratings and relationship weightings in the HOQs so that inconsistencies due to subjective judgments can be avoided. Based on the ranked criteria, alternative 3PLs are evaluated and compared with each other using fuzzy AHP again to make an optimal selection.

\section{Literature review}

Various multi-criteria decision making approaches have been proposed to tackle the logistics outsourcing problem. Menon et al. (1998) proposed nine criteria for the 3PL evaluation and selection, including price, on-time delivery, error rate, financial stability, creative management, meet or exceed promises, availability of top management, responsive to unforeseen problems, and meet performance and quality requirements.

Meade and Sarkis (2002) applied ANP to select the best third-party reverse logistics service provider. The decision factors and clusters considered in the ANP model include location of product in its lifecycle, the organizational performance criteria, the reverse logistics process functions required by the organization, and the organizational role of reverse logistics.

Bottani and Rizzi (2006) developed a fuzzy TOPSIS approach to rank and select the most suitable 3PL with respect to nine criteria, including compatibility, financial stability, flexibility of service, performance, price, physical equipment and information systems, quality, strategic attitude, and trust and fairness.

Işıklar et al. (2007) presented an integrated approach, combining CBR, RBR, and compromise programming, to deal with the 3PL selection problem. The evaluating criteria include cost, quality, technical capability, financial stability, successful track record, service category, personnel qualification, information technology, comparable culture, region, and so on.

Jharkharia and Shankar (2007) deployed the ANP approach to select the optimal 3PL with respect to four major determinants or criteria, such as compatibility, cost, quality, and reputation.

Göl and Çatay (2007) adopted the AHP approach to select an appropriate 3PL. In the AHP hierarchy, there were five evaluating criteria (general company considerations, capabilities, quality, client relationship, and labor relations), in which multiple sub-factors were proposed. 
Efendigil et al. (2008) proposed an integrated approach, combining fuzzy AHP and ANN, to select the best third-party reverse logistics provider. 12 factors were considered, including on-time delivery, fill rate, service quality, unit operation cost, capacity usage, total order cycle time, system flexibility index, integration level, increment in market share, research and development, environmental expenditures, and customer satisfaction.

Zhou et al. (2008) utilized the DEA to measure the efficiencies of Chinese 3PLs. There were four inputs (net fixed asset, salaries and wages, operating expenses, and current liabilities) and one output (operating income) variables in the DEA model.

Qureshi et al. (2008) developed an interpretive structural modeling based approach to identify and classify the key criteria, and to study their role in the assessment of 3PLs. There were 15 criteria - service quality, size and quality of fixed assets, quality of management, IT capability, delivery performance, information sharing and trust, operational performance, compatibility, financial stability, geographic spread and range, long-term relationship, reputation, optimum cost, surge capacity, and flexibility in operation and delivery.

Liu and Wang (2009) presented a three-stage approach for the evaluation and selection of 3PLs. At the first stage, a fuzzy Delphi method was used to identify important evaluation criteria. Then, a fuzzy inference method was applied to estimate unsuitable 3PLs. At the final stage, a fuzzy linear assignment approach was developed for the final selection.

There are two drawbacks in the above approaches. First, they fail to consider the impact of business objectives and the requirements of company stakeholders into the identification of evaluating criteria. The selected 3PL cannot provide what the outsourcing firms exactly need (Ho et al., 2011). To overcome this problem, the proposed approach provides a platform for stakeholders in various functional departments to express their objectives and requirements explicitly, and then translate the requirements into various criteria for performance measurement. Thus, the evaluating factors are related to the strategic intent of company through the involvement of concerned stakeholders. This ensures successful strategic outsourcing because the selected 3PL can achieve the business objectives. Second, natural disasters, accidents, and volatility of the financial market have made the supply chain vulnerable nowadays (Zegordi and Davarzani, 2012). Thus, identifying, analyzing, and responding to risk events proactively are critical in minimizing disruption and losses in supply chains. However, risk-based factors were not considered in the above approaches. 


\section{Integrated QFD and fuzzy AHP approach}

The integrated QFD and fuzzy AHP approach comprises of three HOQs, including HOQ1 - linking company stakeholders with their requirements (steps 1 to 5), HOQ2 relating stakeholder requirements to evaluating criteria (steps 6 to 9), and HOQ3 benchmarking alternative 3PLs with respect to various criteria (steps 10 to 13).

Note that the triangular fuzzy membership function and its operational rules are introduced in the AHP to fuzzify and calculate the pairwise comparison results, and thus the traditional AHP becomes the fuzzy AHP.

Each pairwise comparison result is a fuzzy number $\left(\tilde{F} \mid \mu_{F}(t)\right)$ which possesses the characteristics of triangular fuzzy membership function. The triangular fuzzy number can be expressed as $\tilde{F}=\left(t_{1}, t_{2}, t_{3}\right)$ and equation (3-1) shows its membership function.

$$
\mu_{F}(x)=\left\{\begin{array}{cc}
0 & x<t_{1} \\
\left(x-t_{1}\right)\left(t_{2}-t_{1}\right) & t_{1} \leq x \leq t_{2} \\
\left(x-t_{3}\right)\left(t_{2}-t_{3}\right) & t_{2} \leq x \leq t_{3} \\
0 & x>t_{3}
\end{array}\right.
$$

Where $t_{1}$ denotes the probable minimum value of all the pairwise comparison result, $t_{2}$ is the most probable value, and $t_{3}$ is probable maximum value.

For the two triangular fuzzy numbers $\tilde{F}_{1}=\left(t_{1}, t_{2}, t_{3}\right)$ and $\tilde{F}_{2}=\left(r_{1}, r_{2}, r_{3}\right)$ with the principle proposed by Zadeh (1965) and the features of triangular fuzzy numbers presented by Liang and Wang (1991), the extended algebraic operations on triangular fuzzy numbers can be expressed as follows:

$$
\begin{array}{ll}
\text { Addition: } & \widetilde{F}_{1} \oplus \tilde{F}_{2}=\left(t_{1}+r_{1}, t_{2}+r_{2}, t_{3}+r_{3}\right) \\
\text { Subtraction: } & \widetilde{F}_{1}-\widetilde{F}_{2}=\left(t_{1}-r_{1}, t_{2}-r_{2}, t_{3}-r_{3}\right) \\
\text { Multiplication: } & \widetilde{F}_{1} \otimes \widetilde{F}_{2}=\left(t_{1} * r_{1}, t_{2} * r_{2}, t_{3} * r_{3}\right) \\
\text { Division: } & \widetilde{F}_{1} \div \widetilde{F}_{2}=\left(t_{1} / r_{1}, t_{2} / r_{2}, t_{3} / r_{3}\right) \\
\text { Reciprocal: } & \frac{1}{\tilde{F}_{1}}=\left(\frac{1}{t_{3}}, \frac{1}{t_{2}}, \frac{1}{t_{1}}\right)
\end{array}
$$

The triangular fuzzy numbers are easy to use and interpret. For example, in the 9-point scale, “approximately moderate or 3” can be represented by (2.8, 3.0, 3.1), “approximately 
between strong and very strong” can be represented by $(4.5,6,7.5)$, and the non-fuzzy number 9 can be represented by $(9,9,9)$,

As to the triangular fuzzy numbers which are continuous weights, this paper employs the center of gravity method to defuzzify them using equation (3-7).

$$
F=\int x * \mu_{F}(x) d_{x} / \int \mu_{F}(x) d_{x}
$$

Based on above, this paper proposes the integrated QFD and fuzzy AHP approach as follows.

Step 1: Identify the company stakeholders who have a say in the 3PL selection process.

Step 2: Determine the importance rating of each stakeholder category using fuzzy AHP (steps 2.1 to 2.7 ).

Step 2.1: Fuzzy-based AHP pairwise comparison

Construct a fuzzy pairwise comparison matrix,

$$
\tilde{A}=\left[\begin{array}{cccc}
\tilde{a}_{11} & \tilde{a}_{12} & \cdots & \tilde{a}_{1 n} \\
\tilde{a}_{21} & \tilde{a}_{22} & \cdots & \tilde{a}_{2 n} \\
\vdots & \vdots & \ddots & \vdots \\
\tilde{a}_{n 1} & \tilde{a}_{n 2} & \cdots & \tilde{a}_{n n}
\end{array}\right]
$$

where $n$ denotes the number of elements (i.e., number of stakeholder categories), and $\tilde{a}_{i j}$ refers to the fuzzy comparison number of element $i$ to element $j$ with respect to each criterion. The 9-point scale, shown in Table 1, can be used to decide on which element is more important and by how much.

Step 2.2: $\quad$ Fuzzy-based AHP synthesization

Divide each entry $\left(\tilde{a}_{i j}\right)$ in each column of matrix $\tilde{A}$ by its column total. The matrix now becomes a normalized pairwise comparison matrix,

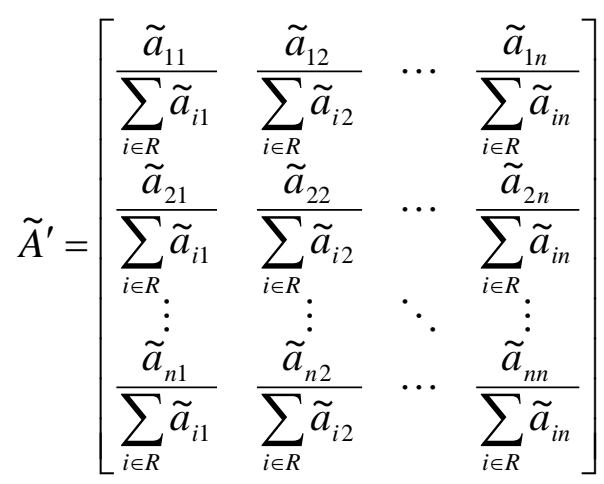


where $R$ denotes the set of stakeholder categories, that is, $R=\{1,2$, $\ldots, n\}$.

Step 2.3: Compute the average of the entries in each row of matrix $\tilde{A}^{\prime}$ to yield column vector,

$$
C=\left[\begin{array}{c}
c_{1 k}^{1} \\
\vdots \\
c_{n k}^{1}
\end{array}\right]=\left[\begin{array}{c}
\frac{\left(\begin{array}{c}
\frac{\tilde{a}_{11}}{\sum_{i \in R} \tilde{a}_{i 1}}+\frac{\tilde{a}_{12}}{\sum_{i \in R} \tilde{a}_{i 2}}+\cdots+\frac{\tilde{a}_{1 n}}{\sum_{i \in R} \tilde{a}_{i n}} \\
n \\
\vdots \\
\frac{\tilde{a}_{n 1}}{\sum_{i \in R} \tilde{a}_{i 1}}+\frac{\tilde{a}_{n 2}}{\sum_{i \in R} \tilde{a}_{i 2}}+\cdots+\frac{\tilde{a}_{n n}}{\sum_{i \in R} \tilde{a}_{i n}}
\end{array}\right)}{n}
\end{array}\right]
$$

where $c_{i k}^{1}$ denotes the importance ratings of stakeholder category $i$.

Step 2.4: $\quad$ Fuzzy-based AHP consistency verification

Multiply each entry in column $i$ of matrix $\tilde{A}$ by $c_{i k}^{1}$. Then, divide the summation of values in row $i$ by $c_{i k}^{1}$ to yield another column vector,

$$
\bar{C}=\left[\begin{array}{c}
\bar{c}_{1 k}^{1} \\
\vdots \\
\bar{c}_{n k}^{1}
\end{array}\right]=\left[\begin{array}{c}
\frac{c_{1 k}^{1} \tilde{a}_{11}+c_{2 k}^{1} \tilde{a}_{12}+\cdots c_{n k}^{1} \tilde{a}_{1 n}}{c_{1 k}^{1}} \\
\vdots \\
\frac{c_{1 k}^{1} \tilde{a}_{n 1}+c_{2 k}^{1} \tilde{a}_{n 2}+\cdots c_{n k}^{1} \tilde{a}_{n n}}{c_{n k}^{1}}
\end{array}\right]
$$

where $\bar{C}$ refers to a weighted sum vector.

Step 2.5: Compute the averages of values in vector $\bar{C}$ to yield the maximum eigenvalue of matrix $\tilde{A}$,

$$
\lambda_{\max }=\frac{\sum_{i \in R} \bar{c}_{i k}^{1}}{n}
$$

Step 2.6: Compute the consistency index,

$$
C I=\frac{\lambda_{\max }-n}{n-1}
$$

Step 2.7: Compute the consistency ratio,

$$
C R=\frac{C I}{R I(n)}
$$


where $R I(n)$ is a random index of which the value is dependent on the value of $n$, shown in Table 2. If $C R$ is greater than 0.10 , then go to step 2.1. Otherwise, go to step 3.

Step 3: Identify the stakeholder requirements.

Step 4: Determine the relationship weightings of stakeholder requirement $i$ and its corresponding stakeholder $k$ using fuzzy AHP (steps 2.1 to 2.7), that is, $c_{i k}^{2}$. Note that $R$ denotes the set of stakeholder requirements, that is, $R=\{1,2, \ldots, n\}$, whereas $S$ denotes the set of stakeholder categories, that is, $S=\{1,2, \ldots, m\}$.

Step 5: Compute the importance rating of each stakeholder requirement,

$$
w_{i}^{1}=\sum_{k \in S} c_{k}^{1} c_{i k}^{2}
$$

where $c_{k}^{1}$ are the importance ratings of stakeholder $k$.

Step 6: Copy the stakeholder requirements (step 3) and their corresponding importance ratings (step 5) into HOQ2.

Step 7: $\quad$ Identify the 3PL evaluating factors.

Step 8: Determine the relationship weightings between evaluating factors $i$ and its corresponding stakeholder requirements $k, c_{i k}^{3}$, using fuzzy AHP (steps 2.1 to 2.7). Note that, in HOQ2, $R$ denotes the set of evaluating factors, that is, $R=\{1$, $2, \ldots, n\}$, whereas $S$ denotes the set of stakeholder requirements, that is, $S=\{1,2$, $\ldots, m\}$.

Step 9: Compute the importance rating of each evaluating factor,

$$
w_{i}^{2}=\sum_{k \in S} w_{k}^{1} C_{i k}^{3}
$$

Step 10: Copy the evaluating factors (step 7) and their corresponding importance ratings (step 9) into HOQ3.

Step 11: $\quad$ Identify alternative 3PLs.

Step 12: Determine the relationship weightings between 3PL $i$ and its corresponding evaluating factors $k, c_{i k}^{4}$, using fuzzy AHP (steps 2.1 to 2.7). Note that, in HOQ3, $R$ denotes the set of alternative 3PLs, that is, $R=\{1,2, \ldots, n\}$, whereas $S$ denotes the set of evaluating factors, that is, $S=\{1,2, \ldots, m\}$.

Step 13: Finally, calculate the total score of each 3PL,

$$
w_{i}^{3}=\sum_{k \in S} w_{k}^{2} c_{i k}^{4}
$$




\section{Case study}

Company A is a Hong Kong based enterprise that supplies hard disk components all over the world. The enterprise has manufacturing plants in China and regional offices in US, Japan, Korea, and Singapore. Recently, the company has decided to outsource three logistics functions, including freight forwarding, out-bound transportation, and inventory management.

The reasons for outsourcing these functions are as follows. First, the company is not capable of handling the freight forwarding operation. In general, air freight forwarders rent the air containers from the airlines, and consolidate all customers' shipments and pack in the air containers to achieve cost effectiveness. Firms seldom contact airlines directly as air freight forwarders can help the shippers to prepare shipping documents, tender shipments to the airlines, and provide pick and pack services.

Second, the company has to provide the hard disk components regularly to meet the urgent needs of customers. The company reveals that it is more efficient if the products are shipped directly from manufacturing plants in China by the 3PL rather than the internal logistics team. It is because the 3PL will help the company to save time in handling the custom clearances, especially in small batch production. Due to this reason, Company A prefers outsourcing the cross-border transportation to shipping by the internal logistics team.

Third, the company intends to request the 3PL to manage the inventory, including the determination of the appropriate inventory level for each product type, and the appropriate inventory policies.

The company recently evaluated the performance of four alternative 3PLs (A1, A2, A3, and A4). The aim of this evaluation was to determine 3PL performance in terms of the ability of satisfying the company's requirements most.

The following paragraphs demonstrate the application of proposed approach using stepby-step approach.

Step 1: Identify the company stakeholders

To evaluate and select the best 3PL for the above three services, the company stakeholders who have a say in selection process were identified first. In this case, there are four categories: finance, logistics/transportation, manufacturing, and marketing.

Step 2: Determine the importance rating of each stakeholder category

The importance rating of each stakeholder category needed to be determined by the company's management team using fuzzy AHP. A stakeholder with a higher importance 
rating means that $\mathrm{s}$ /he has more impact on the selection process. Summation of the importance ratings is equal to one.

The first step was to construct a fuzzy pairwise comparison matrix (Figure 1). For synthesization, a normalized fuzzy comparison matrix was constructed (Figure 2). Based on matrix $\tilde{A}^{\prime}$, a column vector showing the importance ratings of stakeholders was constructed (Figure 3). To verify the consistency, a weighted sum vector was constructed (Figure 4). Then, the maximum eigenvalue of matrix $\tilde{A}$, consistency index, and consistency ratio were computed. Because $C R$ is less than 0.10, the fuzzy pairwise comparison is consistent.

$$
\begin{gathered}
\lambda_{\max }=\frac{4.229+4.446+4.102+4.042}{4}=4.205 \\
C I=\frac{4.205-4}{4-1}=0.068 \\
C R=\frac{0.068}{0.90}=0.076
\end{gathered}
$$

Step 3: Identify the stakeholder requirements

In the third step, the stakeholder requirements were identified through a brainstorming session among the identified stakeholders. The brainstorming session resulted eight stakeholder requirements. They are shown in Table 3.

Step 4: Determine the relationship weightings between the company stakeholders and stakeholder requirements using fuzzy AHP

Note that the size of each fuzzy pairwise comparison matrix is not the same. For the finance department, the matrix is 6-by-6 because the fourth requirement (Provide customized logistics services) and the seventh requirement (Able to provide guidance on time) are not of interest to the finance department. On the other hand, there were eight elements in the matrix for the logistics/transportation department because all the eight requirements were related to them.

Step 5: Compute the importance rating of each stakeholder requirement

Following the fuzzy AHP approach for determining the importance ratings of stakeholders (step 2) and relationship weightings between the stakeholder requirements and stakeholders (step 4), the importance rating of each stakeholder requirement was computed in HOQ1 as shown in Figure 5.

Step 6: Copy the stakeholder requirements (step 3) and their corresponding importance ratings (step 5) into HOQ2. 
After completing HOQ1, both stakeholder requirements and their corresponding importance ratings were copied into HOQ2, which linked the requirements and evaluating factors.

Step 7: $\quad$ Identify the 3PL evaluating factors

In this HOQ, stakeholder requirements were regarded as “what's”, whereas evaluating factors were akin to "how's". The evaluating factors were proposed by the stakeholders according to the results of a questionnaire. In this case, there were 20 evaluating factors that the 3PL should possess in order to achieve the stakeholder requirements. Table 4 shows the list of evaluating criteria and their sub-factors.

Step 8: Determine the relationship weights between evaluating factors and its corresponding stakeholder requirements

Similar to HOQ1, fuzzy AHP was used to calculate the relationship weightings between the stakeholder requirements and evaluating factors in HOQ2. Certainly, the size of each pairwise comparison matrix was varied, and was dependent on the number of evaluating factors that will achieve a particular requirement.

Step 9: Compute the importance rating of each evaluating factor

After determining all relationship weightings between the eight stakeholder requirements and their related evaluating factors, the importance ratings of each factor were computed in HOQ2 as shown in Figure 6. According to HOQ2, the 10 most critical factors for the three outsourced logistics functions (freight forwarding, out-bound transportation, and inventory management) were “On-time delivery”, “Physical equipment”, “Information system capabilities”, “Compatibility with the users”, “Optimization capabilities”, "Delivery condition”, “Accuracy of quantity fulfilment”, “Service category”, “Ability in identifying and preventing potential problems”, and "Perfect rate”.

Step 10: Copy the evaluating factors (step 7) and their corresponding importance ratings (step 9) into HOQ3.

At the last stage, both evaluating factors and their corresponding importance ratings were copied into HOQ3, which evaluates the 3PLs with respect to the 20 evaluating factors.

Step 11: Identify the alternative 3PLs

As mentioned earlier, there were four alternatives to be evaluated. They were shortlisted because they satisfied the minimum specifications of Company A.

Step 12: Determine the relationship weightings between 3PLs and evaluating factors

Fuzzy AHP was used again to calculate the relationship weightings between the evaluating factors and 3PLs in HOQ3. 
Step 13: Finally, calculate the total score of each 3PL

After determining all relationship weightings, the importance rating of each 3PL was computed in HOQ3 as shown in Figure 7. According to HOQ3, the performance of the third 3PL is the best, followed by A1, A4, and A2. Therefore, Company A should outsource the freight forwarding, out-bound transportation, and inventory management services to the third 3PL. Alternatively, the performance of 3PLs can be evaluated with respect to some critical factors instead of all 20 factors. Based on the 10 critical factors mentioned in step 9, the performance of A3 was the best (0.311), followed by A1 (0.223), A4 (0.144), and A2 (0.082). According to both evaluations, the company should collaborate with the third 3PL.

\section{Result analysis}

In this section, we will benchmark alternative 3PLs with respect to the six evaluating criteria - cost, delivery, flexibility, quality, technology, and risk. The factors of each criterion will be analyzed to understand why the third 3PL (A3) outperforms the others, and examine how this selection will be beneficial to the hard disk component manufacturing company.

The first criterion is "cost", in which there are three factors as shown in Table 5. A2 performs the best in this category because it is proactive in reducing cost, and provides the lowest cost solutions. Nevertheless, it concerns less on the other five criteria, which will lead to low level of customer satisfaction because of lengthy delivery time, poor quality of service, lack of communication, and so on.

The comparison of alternative 3PLs with respect to "delivery" is shown in Table 6. Because of having a large fleet size and reliable vehicle routing optimization package, A3 has the best performance in terms of on-time delivery and accuracy of quantity fulfilment. Besides, A3 possesses secured handling equipment, safety packaging tool, and well-trained staff with special care. It is the second best 3PL in terms of delivery condition.

According to Table 7, A3 scores the highest in all factors of "flexibility" criterion. Instead of providing standardized and limited logistics services, A3 is able to adapt to the outsourcing companies to provide customized services (i.e., Compatibility with the users) and various kinds of value-added services (i.e., Service category), respectively. A3 is also capable of increasing its internal capacity and acquiring external capacity from sub-contractors to meet unpredictable high demand (i.e., Flexibility in increasing production capacity).

The comparison of alternative 3PLs with respect to "quality" is shown in Table 8. A3 gets the highest score because it is highly recommended by the existing customers for its high logistics performance (i.e., References from current customers), and is committed to provide 
and improve high quality of services continuously and consistently (i.e., Reliability of quality). Besides, A3 has the second highest perfect rate, and is the second best 3PL in terms of implementing the total quality management program, for example, statistical process control for monitoring the process quality of individual logistics activities.

The comparison of alternative 3PLs with respect to "technology" is shown in Table 9. A1 possesses comprehensive information systems, including EDI and extranet, for its users or the outsourcing companies to place orders online, seek advice and guidance virtually. Besides, A1 has invested the most on the optimization software (e.g., vehicle routing, carrier loading, consolidation), and physical equipment (e.g., vehicles, material handling devices, RFID devices, bar coding printers and scanners, track-and-trace devices). A3 is in the second place in this category.

Finally, the comparison of alternative 3PLs with respect to "risk" is shown in Table 10. Again, S3 gets the highest score because it has the know-how to identify potential problems and prevent some of them from happening (i.e., Ability in identifying and preventing potential problems). If risks occur, A3 is able to take remedial actions to mitigate the impact of problems on the outsourcing companies (i.e., Risk mitigating skills). Moreover, A3 is financially sound and credit worthy (i.e., Financial stability). Besides, the contact persons of A3 are accessible and helpful in dealing with emergent situations at most of the time (i.e., Accessibility of contact persons in emergency).

Based on the above analysis, there are numerous advantages of outsourcing the logistics activities to A3. In summary, this 3PL selection will help to enhance the competitiveness of hard disk components manufacturing company. Evaluating 3PLs with respect to cost-based factors cannot guarantee that the selected 3PL is optimal in terms of satisfying the business objectives and company stakeholders' needs because multiple criteria should be considered, as the proposed approach did.

\section{Conclusions}

This paper developed an integrated multiple criteria fuzzy decision-making approach to measure the performance of alternative 3PLs. A case study was given to demonstrate how it works. In the approach, QFD was used to translate the hard disk components manufacturing company stakeholder requirements into 20 evaluating factors, which were used to benchmark the 3PLs. Fuzzy AHP was used to determine both importance ratings and relationship weightings in HOQs consistently. The major advantage of this integrated approach is that the evaluating factors are of interest to the stakeholders. This ensures that the selected 3PL will 
achieve the business objectives and satisfy the stakeholders most. Another advantage is that the approach can guarantee the benchmarking to be consistent and reliable. Furthermore, the integrated approach involves a team of people representing various functional departments that have involvement in 3PL selection: finance, logistics/transportation, manufacturing, and marketing. The active involvement of these departments can lead to a balanced consideration of the requirements or "what's" at each stage of this translation process, and provide a mechanism to communicate implicit knowledge - knowledge that is known by one individual or department but may not otherwise be communicated through the company. Therefore, the proposed approach outranks the conventional approaches to strategic logistics outsourcing. In the immediate future, a sensitivity analysis should be carried out in order to check the effect of changes in the importance levels of various factors on final outcome. 


\section{References}

Bottani, E., Rizzi, A., 2006. A fuzzy TOPSIS methodology to support outsourcing of logistics services. Supply Chain Management: An International Journal 11, 294-308.

Efendigil, T., Önüt, S., Kongar, E., 2008. A holistic approach for selecting a third-party reverse logistics provider in the presence of vagueness. Computers \& Industrial Engineering 54, 269-287.

Göl, H., Çatay, B., 2007. Third-party logistics provider selection: Insights from a Turkish automotive company. Supply Chain Management: An International Journal 12, 379_ 384.

Ho, W., Dey, P.K., Lockström, M., 2011. Strategic sourcing: a combined QFD and AHP approach in manufacturing. Supply Chain Management: An International Journal 16, 446-461.

Iş1klar, G., Alptekin, E., Büyüközkan, G., 2007. Application of a hybrid intelligent decision support model in logistics outsourcing. Computers \& Operations Research 34, 37013714.

Jharkharia, S., Shankar, R., 2007. Selection of logistics service provider: An analytic network process (ANP) approach. Omega 35, 274-289.

Liang, G.S., Wang, M.J., 1991. A fuzzy multi-criteria decision-making method for facility site selection. International Journal of Production Research 29, 2313-2330.

Liu, H.T., Wang, W.K., 2009. An integrated fuzzy approach for provider evaluation and selection in the third-party logistics. Expert Systems with Applications 36, 4387-4398.

Meade, L., Sarkis, J., 2002. A conceptual model for selecting and evaluating third-party reverse logistics providers. Supply Chain Management: An International Journal 7, 283-295.

Menon, M.K., McGinnis, M.A., Ackerman, K.B., 1998. Selection criteria for providers of third-party logistics services: An exploratory study. Journal of Business Logistics 19, 121-137.

Qureshi, M.N., Kumar, D., Kumar, P., 2008. An integrated model to identify and classify the key criteria and their role in the assessment of 3PL service providers. Asia Pacific Journal of Marketing and Logistics 20, 227-249.

Razzaque, M.A., Sheng, C.C., 1998. Outsourcing of logistics functions: A literature survey. International Journal of Physical Distribution \& Logistics Management 28, 89-107.

Sink, H.L., Langley, C.J., 1997. A managerial framework for the acquisition of third-party logistics services. Journal of Business Logistics 18, 163-189. 
Zadeh, L.A., 1965. Fuzzy sets. Information and Control 8, 338-353.

Zegordi, S.H., Davarzani, H., 2012. Developing a supply chain disruption analysis model: Application of colored Petri-nets. Expert Systems with Applications 39, 2102-2111.

Zhou, G., Min, H., Xu, C., Cao, Z., 2008. Evaluating the comparative efficiency of Chinese third-party logistics providers using data envelopment analysis. International Journal of Physical Distribution \& Logistics Management 38, 262-279. 


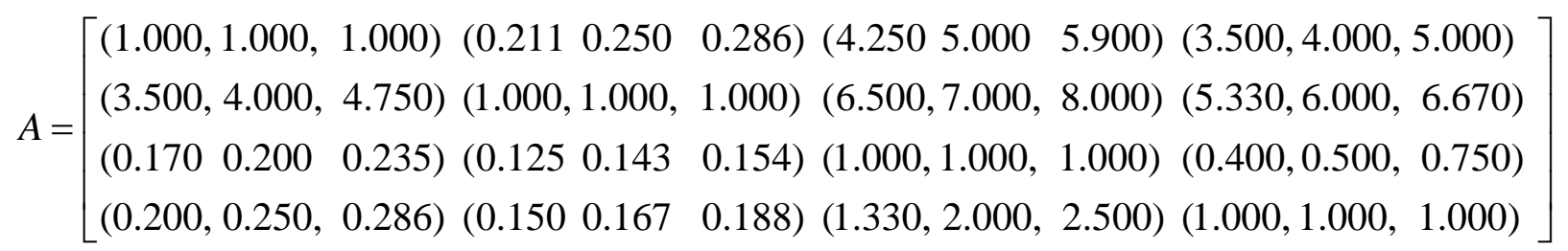

Figure 1: Pairwise comparison matrix

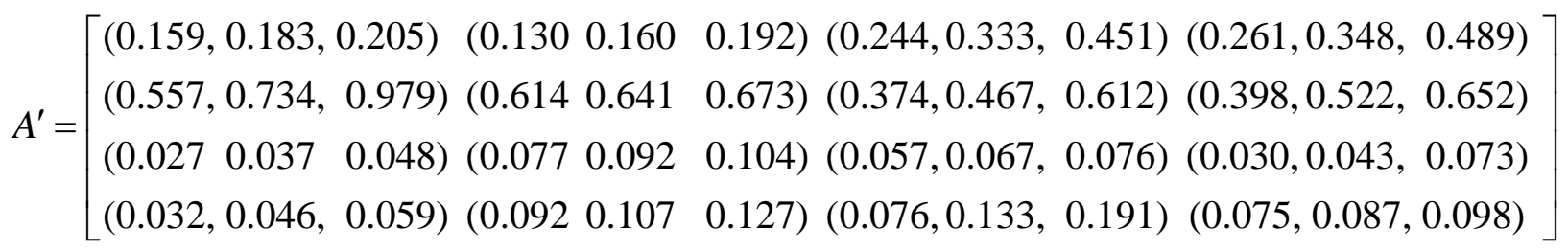

Figure 2: Normalized pairwise comparison matrix

$$
C=\left[\begin{array}{lll}
(0.795 & 1.025 & 1.337) \\
(1.943 & 2.363 & 2.916) \\
(0.191 & 0.239 & 0.302) \\
(0.275 & 0.373 & 0.475)
\end{array}\right]
$$

Figure 3: Column vector

$$
\bar{C}=\left[\begin{array}{l}
4.229 \\
4.446 \\
4.102 \\
4.042
\end{array}\right]
$$

Figure 4: Weighted sum vector 


\begin{tabular}{|c|c|c|c|c|c|c|c|c|c|}
\hline \multirow[b]{2}{*}{ Company stakeholders } & \multirow[b]{2}{*}{ 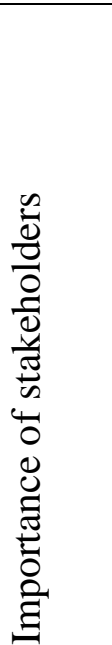 } & \multicolumn{8}{|c|}{ Stakeholder requirements } \\
\hline & & 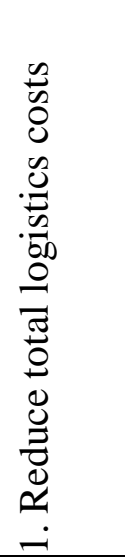 & 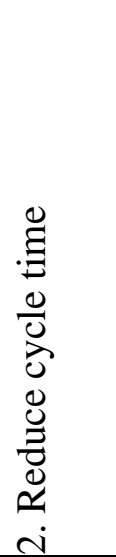 & 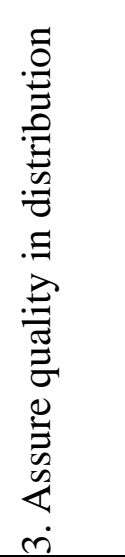 & 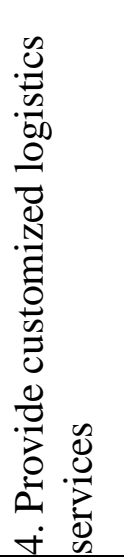 & 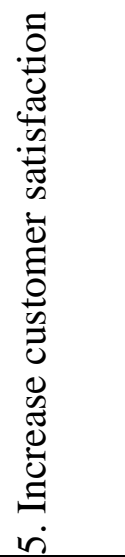 & 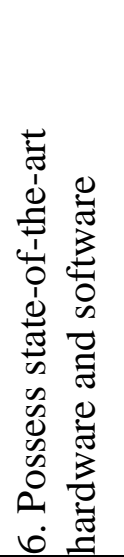 & 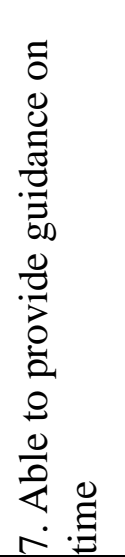 & 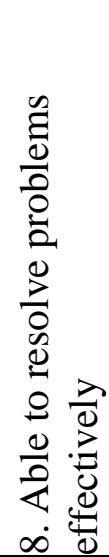 \\
\hline 1. Finance & 0.258 & 0.442 & 0.224 & 0.060 & & 0.042 & 0.094 & & 0.149 \\
\hline 2. Logistics/Transportation & 0.600 & 0.024 & 0.261 & 0.120 & 0.245 & 0.033 & 0.177 & 0.060 & 0.080 \\
\hline 3. Manufacturing & 0.058 & & 0.303 & 0.063 & 0.292 & & 0.177 & 0.072 & 0.097 \\
\hline 4. Marketing & 0.092 & 0.102 & 0.163 & 0.251 & & 0.382 & 0.048 & & 0.057 \\
\hline $\begin{array}{l}\text { Importance ratings of } \\
\text { stakeholder requirements }\end{array}$ & & 0.138 & 0.247 & 0.114 & 0.164 & 0.066 & 0.145 & 0.040 & 0.097 \\
\hline Ranking & & 4th & $1 \mathrm{st}$ & 5th & 2nd & 7th & 3rd & 8th & 6th \\
\hline
\end{tabular}

Figure 5: HOQ1 - linking company stakeholders and their requirements 


\begin{tabular}{|c|c|c|c|c|c|c|c|c|c|c|c|}
\hline \multirow[b]{2}{*}{ Stakeholder requirements } & \multirow[b]{2}{*}{ 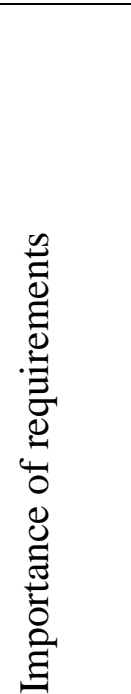 } & \multicolumn{10}{|c|}{ Evaluating factors } \\
\hline & & 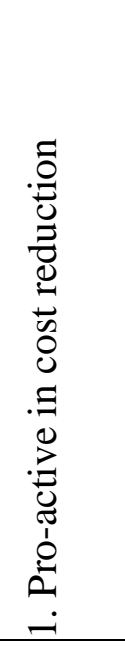 & 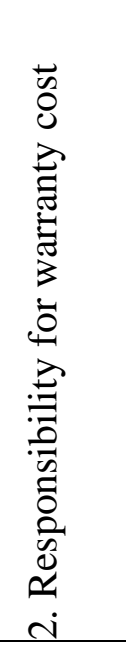 & 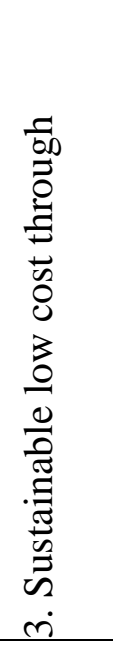 & 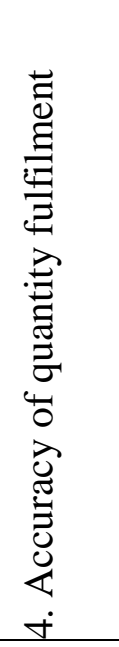 & 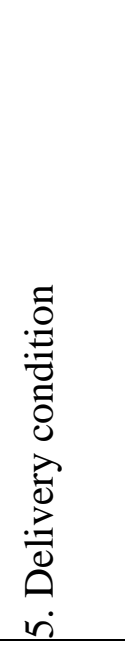 & 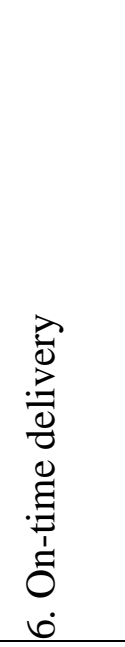 & 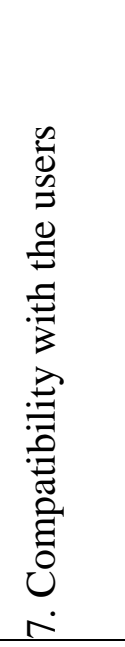 & 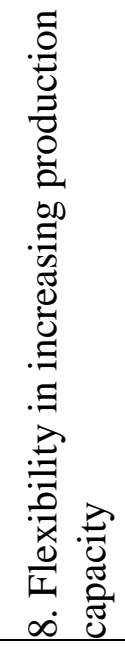 & 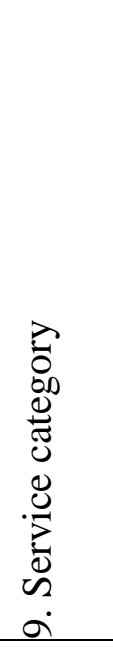 & 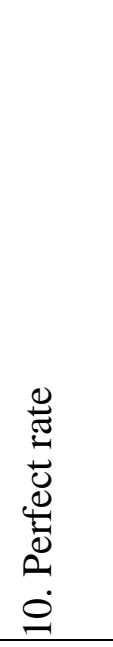 \\
\hline 1. Reduce total logistics costs & 0.138 & 0.315 & 0.170 & 0.315 & & & & & & & \\
\hline 2. Reduce cycle time & 0.247 & & & & 0.232 & 0.033 & 0.380 & & & & \\
\hline 3. Assure quality in distribution & 0.114 & & & & & 0.423 & & & & & 0.265 \\
\hline $\begin{array}{l}\text { 4. Provide customized logistics } \\
\text { services }\end{array}$ & 0.164 & & & & & & & 0.383 & 0.033 & 0.256 & \\
\hline 5. Increase customer satisfaction & 0.066 & & & & 0.085 & 0.125 & 0.277 & & & & 0.256 \\
\hline $\begin{array}{l}\text { 6. Possess state-of-the-art hardware } \\
\text { and software }\end{array}$ & 0.145 & & & & & & & 0.110 & & 0.084 & \\
\hline 7. Able to provide guidance on time & 0.040 & & & & & & & 0.257 & & & \\
\hline $\begin{array}{l}\text { 8. Able to resolve problems } \\
\text { effectively }\end{array}$ & 0.097 & & & & & & & & & & \\
\hline $\begin{array}{l}\text { Importance ratings of evaluating } \\
\text { factors }\end{array}$ & & 0.043 & 0.023 & 0.043 & 0.063 & 0.065 & 0.112 & 0.089 & 0.005 & 0.054 & 0.047 \\
\hline Ranking & & 11th & 17th & 11th & 7th & 6th & 1st & 4th & 19th & 8th & 10th \\
\hline
\end{tabular}

Figure 6: HOQ2 - linking stakeholder requirements and evaluating factors 


\begin{tabular}{|c|c|c|c|c|c|c|c|c|c|c|c|}
\hline \multirow[b]{2}{*}{ Stakeholder requirements } & \multirow[b]{2}{*}{ 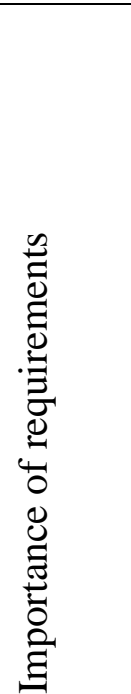 } & \multicolumn{10}{|c|}{ Evaluating factors } \\
\hline & & 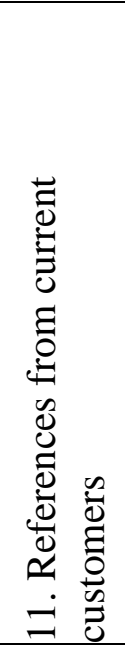 & 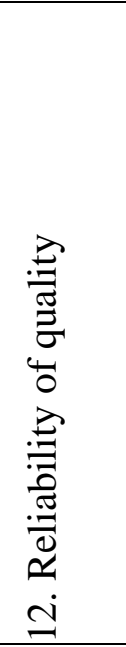 & 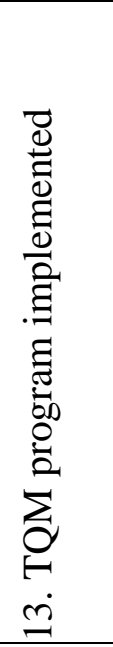 & 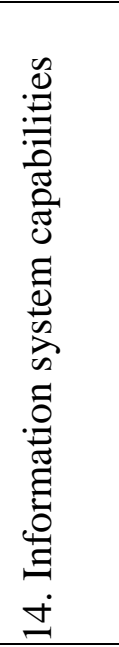 & 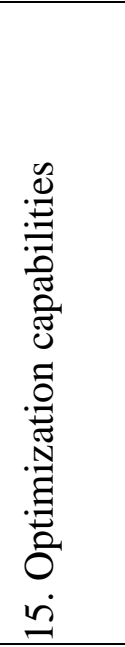 & 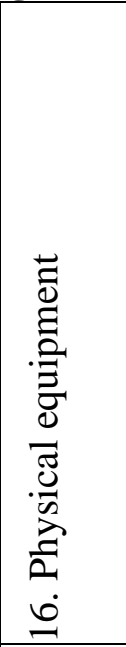 & 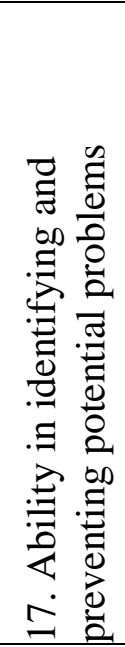 & 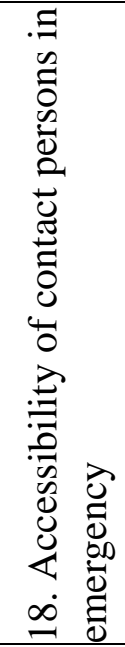 & 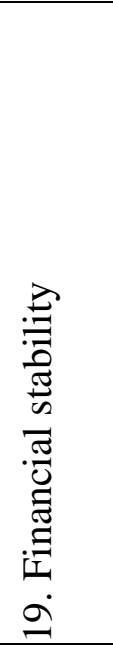 & 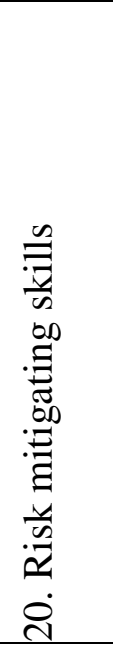 \\
\hline 1. Reduce total logistics costs & 0.138 & & & & 0.053 & 0.047 & & & & 0.108 & \\
\hline 2. Reduce cycle time & 0.247 & & & & 0.146 & 0.113 & 0.101 & & & & \\
\hline 3. Assure quality in distribution & 0.114 & & 0.164 & 0.049 & & & 0.105 & & & & \\
\hline $\begin{array}{l}\text { 4. Provide customized logistics } \\
\text { services }\end{array}$ & 0.164 & & & & 0.096 & 0.082 & 0.151 & & & & \\
\hline 5. Increase customer satisfaction & 0.066 & 0.027 & 0.135 & 0.056 & 0.037 & & & & & & \\
\hline $\begin{array}{l}\text { 6. Possess state-of-the-art hardware } \\
\text { and software }\end{array}$ & 0.145 & & & & 0.269 & 0.233 & 0.305 & & & & \\
\hline 7. Able to provide guidance on time & 0.040 & & & & 0.060 & 0.057 & & 0.158 & 0.378 & & 0.098 \\
\hline $\begin{array}{l}\text { 8. Able to resolve problems } \\
\text { effectively }\end{array}$ & 0.097 & & & & & & & 0.460 & 0.158 & 0.089 & 0.297 \\
\hline $\begin{array}{l}\text { Importance ratings of evaluating } \\
\text { factors }\end{array}$ & & 0.002 & 0.028 & 0.009 & 0.103 & 0.084 & 0.106 & 0.051 & 0.030 & 0.024 & 0.033 \\
\hline Ranking & & 20th & 15th & 18th & 3rd & 5th & 2nd & 9th & 14th & 16th & 13th \\
\hline
\end{tabular}

Figure 6: HOQ2 - linking stakeholder requirements and evaluating factors (continue) 


\begin{tabular}{|c|c|c|c|c|c|}
\hline \multirow[b]{2}{*}{ Evaluating factors } & \multirow{2}{*}{ 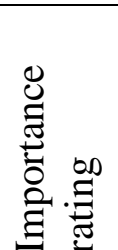 } & \multicolumn{4}{|c|}{ Alternative 3PLs } \\
\hline & & A1 & A2 & A3 & A4 \\
\hline 1. Pro-active in cost reduction & 0.043 & 0.083 & 0.429 & 0.253 & 0.231 \\
\hline 2. Responsibility for warranty cost & 0.023 & 0.110 & 0.120 & 0.270 & 0.493 \\
\hline 3. Sustainable low cost through & 0.043 & 0.091 & 0.492 & 0.188 & 0.232 \\
\hline 4. Accuracy of quantity fulfilment & 0.063 & 0.152 & 0.068 & 0.539 & 0.240 \\
\hline 5. Delivery condition & 0.065 & 0.123 & 0.069 & 0.310 & 0.500 \\
\hline 6. On-time delivery & 0.112 & 0.121 & 0.058 & 0.521 & 0.301 \\
\hline 7. Compatibility with the users & 0.089 & 0.240 & 0.161 & 0.534 & 0.063 \\
\hline $\begin{array}{l}\text { 8. Flexibility in increasing production } \\
\text { capacity }\end{array}$ & 0.005 & 0.198 & 0.290 & 0.427 & 0.091 \\
\hline 9. Service category & 0.054 & 0.240 & 0.115 & 0.577 & 0.073 \\
\hline 10. Perfect rate & 0.047 & 0.114 & 0.053 & 0.393 & 0.435 \\
\hline 11. References from current customers & 0.002 & 0.101 & 0.059 & 0.515 & 0.333 \\
\hline 12. Reliability of quality & 0.028 & 0.162 & 0.062 & 0.531 & 0.249 \\
\hline 13. TQM program implemented & 0.009 & 0.130 & 0.108 & 0.271 & 0.493 \\
\hline 14. Information system capabilities & 0.103 & 0.577 & 0.078 & 0.168 & 0.179 \\
\hline 15. Optimization capabilities & 0.084 & 0.480 & 0.114 & 0.329 & 0.069 \\
\hline 16. Physical equipment & 0.106 & 0.467 & 0.137 & 0.321 & 0.073 \\
\hline $\begin{array}{l}\text { 17. Ability in identifying and preventing } \\
\text { potential problems }\end{array}$ & 0.051 & 0.147 & 0.243 & 0.548 & 0.068 \\
\hline $\begin{array}{l}\text { 18. Accessibility of contact persons in } \\
\text { emergency }\end{array}$ & 0.030 & 0.445 & 0.078 & 0.321 & 0.164 \\
\hline 19. Financial stability & 0.024 & 0.071 & 0.134 & 0.476 & 0.323 \\
\hline 20. Risk mitigating skills & 0.033 & 0.126 & 0.260 & 0.549 & 0.066 \\
\hline Importance ratings of alternative 3PLs & & 0.264 & 0.144 & 0.401 & 0.205 \\
\hline Ranking & & 2nd & 4th & $1 \mathrm{st}$ & 3rd \\
\hline
\end{tabular}

Figure 7: HOQ3 - linking evaluating factors and alternative 3PLs 


\section{Table 1}

AHP pairwise comparison scale

\begin{tabular}{lll}
\hline Intensity & Importance & Explanation \\
\hline 1 & Equal & Two activities contribute equally to the object \\
3 & Moderate & Slightly favors one over another \\
5 & Strong & Strongly favors one over another \\
7 & Very strong & $\begin{array}{l}\text { Dominance of the demonstrated in practice } \\
\text { Evidence favoring one over another of highest } \\
9\end{array}$ \\
Extreme & $\begin{array}{l}\text { possible order of affirmation } \\
\text { When compromise is needed }\end{array}$ \\
$\begin{array}{l}\text { Reciprocals of the } \\
\text { above numbers }\end{array}$ & & For inverse comparison \\
\hline
\end{tabular}

Table 2

List of random index value

\begin{tabular}{lllllllll}
\hline$n$ & 2 & 3 & 4 & 5 & 6 & 7 & 8 & 9 \\
\hline$R I(n)$ & 0 & 0.58 & 0.90 & 1.12 & 1.24 & 1.32 & 1.41 & 1.45 \\
\hline
\end{tabular}




\section{Table 3}

Descriptions of company stakeholder requirements

\begin{tabular}{|c|c|}
\hline Stakeholder requirements & Description \\
\hline $\begin{array}{l}\text { 1. Reduce total logistics } \\
\text { costs }\end{array}$ & $\begin{array}{l}\text { Focus should be confined to minimization of the total logistics } \\
\text { costs rather than minimization of the costs of individual } \\
\text { logistics activities. Total logistics costs include transportation } \\
\text { cost, warehousing cost, material handling cost, packaging } \\
\text { cost, consolidation cost, and so on. }\end{array}$ \\
\hline 2. Reduce cycle time & $\begin{array}{l}\text { Delivering the right amount of products to the right place at } \\
\text { the right time can help to achieve } 100 \% \text { on-time delivery, and } \\
\text { reduce customer waiting time. }\end{array}$ \\
\hline $\begin{array}{l}\text { 3. Assure quality in } \\
\text { distribution }\end{array}$ & $\begin{array}{l}\text { Special equipment, packaging, and care are essential to ensure } \\
\text { safety condition of product delivery, and reduce the chance of } \\
\text { malfunction and damaging. }\end{array}$ \\
\hline $\begin{array}{l}\text { 4. Provide customized } \\
\text { logistics services }\end{array}$ & $\begin{array}{l}\text { Different outsourcing companies will have various specific } \\
\text { requirements on the logistics services. It is critical to select a } \\
\text { 3PL, who is able to provide flexible, tailor-made solutions to } \\
\text { meet their changing needs. }\end{array}$ \\
\hline $\begin{array}{l}\text { 5. Increase customer } \\
\text { satisfaction }\end{array}$ & $\begin{array}{l}\text { The 3PL can help to increase the customer satisfaction by } \\
\text { maintaining high level of service quality. }\end{array}$ \\
\hline $\begin{array}{l}\text { 6. Possess state-of-the-art } \\
\text { hardware and software }\end{array}$ & $\begin{array}{l}\text { Both advanced hardware (e.g., a fleet of vehicles, storing and } \\
\text { handling devices, RFID, GPS satellite tracking device) and } \\
\text { software (vehicle routing packages, carrier loading } \\
\text { optimization software, data transmission and receiving } \\
\text { systems) of the 3PL can help to enhance the competitiveness } \\
\text { of the outsourcing company. }\end{array}$ \\
\hline $\begin{array}{l}\text { 7. Able to provide } \\
\text { guidance on time }\end{array}$ & $\begin{array}{l}\text { It refers to the ability of the 3PL to give advice and provide } \\
\text { insights to the outsourcing company in an efficient and } \\
\text { proactive manner. }\end{array}$ \\
\hline $\begin{array}{l}\text { 8. Able to resolve } \\
\text { problems effectively }\end{array}$ & $\begin{array}{l}\text { It refers to the ability of the } 3 P L \text { to resolve problems and } \\
\text { mitigate the impact of problems on the outsourcing company } \\
\text { in an effective manner. }\end{array}$ \\
\hline
\end{tabular}




\section{Table 4}

A list of 3PL evaluating criteria

\begin{tabular}{|c|c|}
\hline Evaluating criteria & Sub-factors \\
\hline Cost & $\begin{array}{l}\text { Pro-active in cost reduction } \\
\text { Responsibility for warranty cost } \\
\text { Sustainable low cost through }\end{array}$ \\
\hline Delivery & $\begin{array}{l}\text { Accuracy of quantity fulfilment } \\
\text { Delivery condition } \\
\text { On-time delivery }\end{array}$ \\
\hline Flexibility & $\begin{array}{l}\text { Compatibility with the users } \\
\text { Flexibility in increasing production capacity } \\
\text { Service category }\end{array}$ \\
\hline Quality & $\begin{array}{l}\text { Perfect rate } \\
\text { References from current customers } \\
\text { Reliability of quality } \\
\text { TQM program implemented }\end{array}$ \\
\hline Technology & $\begin{array}{l}\text { Information system capabilities } \\
\text { Optimization capabilities } \\
\text { Physical equipment }\end{array}$ \\
\hline Risk & $\begin{array}{l}\text { Ability in identifying and preventing potential problems } \\
\text { Accessibility of contact persons in emergency } \\
\text { Financial stability } \\
\text { Risk mitigating skills }\end{array}$ \\
\hline
\end{tabular}




\section{Table 5}

A comparison of the alternative 3PLs with respect to cost

\begin{tabular}{|c|c|c|c|c|c|}
\hline \multirow[b]{2}{*}{ Evaluating factors } & \multirow[b]{2}{*}{ 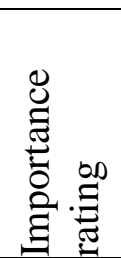 } & \multicolumn{4}{|c|}{ Alternative 3PLs } \\
\hline & & A1 & A2 & A3 & A4 \\
\hline 1. Pro-active in cost reduction & 0.043 & 0.083 & 0.429 & 0.253 & 0.231 \\
\hline 2. Responsibility for warranty cost & 0.023 & 0.110 & 0.120 & 0.270 & 0.493 \\
\hline 3. Sustainable low cost through & 0.043 & 0.091 & 0.492 & 0.188 & 0.232 \\
\hline Importance ratings of alternative 3PLs & & 0.010 & 0.043 & 0.026 & 0.032 \\
\hline Ranking & & 4th & $1 \mathrm{st}$ & 3rd & 2nd \\
\hline
\end{tabular}

Table 6

A comparison of the alternative 3PLs with respect to delivery

\begin{tabular}{|c|c|c|c|c|c|}
\hline \multirow[b]{2}{*}{ Evaluating factors } & \multirow[b]{2}{*}{ 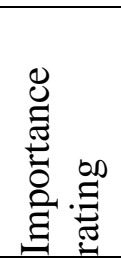 } & \multicolumn{4}{|c|}{ Alternative 3PLs } \\
\hline & & A1 & A2 & A3 & A4 \\
\hline 4. Accuracy of quantity fulfilment & 0.063 & 0.152 & 0.068 & 0.539 & 0.240 \\
\hline 5. Delivery condition & 0.065 & 0.123 & 0.069 & 0.310 & 0.500 \\
\hline 6. On-time delivery & 0.112 & 0.121 & 0.058 & 0.521 & 0.301 \\
\hline Importance ratings of alternative 3PLs & & 0.031 & 0.015 & 0.112 & 0.081 \\
\hline Ranking & & 3rd & 4th & $1 \mathrm{st}$ & 2nd \\
\hline
\end{tabular}

\section{Table 7}

A comparison of the alternative 3PLs with respect to flexibility

\begin{tabular}{|c|c|c|c|c|c|}
\hline \multirow[b]{2}{*}{ Evaluating factors } & \multirow[b]{2}{*}{ 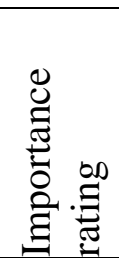 } & \multicolumn{4}{|c|}{ Alternative 3PLs } \\
\hline & & A1 & A2 & A3 & A4 \\
\hline 7. Compatibility with the users & 0.089 & 0.240 & 0.161 & 0.534 & 0.063 \\
\hline $\begin{array}{l}\text { 8. Flexibility in increasing production } \\
\text { capacity }\end{array}$ & 0.005 & 0.198 & 0.290 & 0.427 & 0.091 \\
\hline 9. Service category & 0.054 & 0.240 & 0.115 & 0.577 & 0.073 \\
\hline Importance ratings of alternative 3PLs & & 0.035 & 0.022 & 0.081 & 0.010 \\
\hline Ranking & & 2nd & 3rd & $1 \mathrm{st}$ & 4th \\
\hline
\end{tabular}




\section{Table 8}

A comparison of the alternative 3PLs with respect to quality

\begin{tabular}{|c|c|c|c|c|c|}
\hline \multirow[b]{2}{*}{ Evaluating factors } & \multirow[b]{2}{*}{ 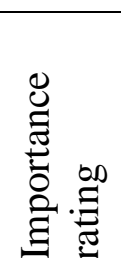 } & \multicolumn{4}{|c|}{ Alternative 3PLs } \\
\hline & & A1 & A2 & A3 & A4 \\
\hline 10. Perfect rate & 0.047 & 0.114 & 0.053 & 0.393 & 0.435 \\
\hline 11. References from current customers & 0.002 & 0.101 & 0.059 & 0.515 & 0.333 \\
\hline 12. Reliability of quality & 0.028 & 0.162 & 0.062 & 0.531 & 0.249 \\
\hline 13. TQM program implemented & 0.009 & 0.130 & 0.108 & 0.271 & 0.493 \\
\hline Importance ratings of alternative 3PLs & & 0.011 & 0.005 & 0.037 & 0.033 \\
\hline Ranking & & 3rd & 4th & $1 \mathrm{st}$ & 2nd \\
\hline
\end{tabular}

Table 9

A comparison of the alternative 3PLs with respect to technology

\begin{tabular}{|c|c|c|c|c|c|}
\hline \multirow[b]{2}{*}{ Evaluating factors } & \multirow[b]{2}{*}{ 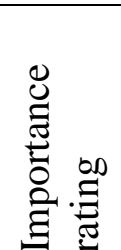 } & \multicolumn{4}{|c|}{ Alternative 3PLs } \\
\hline & & A1 & A2 & A3 & A4 \\
\hline 14. Information system capabilities & 0.103 & 0.577 & 0.078 & 0.168 & 0.179 \\
\hline 15. Optimization capabilities & 0.084 & 0.480 & 0.114 & 0.329 & 0.069 \\
\hline 16. Physical equipment & 0.106 & 0.467 & 0.137 & 0.321 & 0.073 \\
\hline Importance ratings of alternative 3PLs & & 0.149 & 0.032 & 0.079 & 0.032 \\
\hline Ranking & & $1 \mathrm{st}$ & 3rd & 2nd & 3rd \\
\hline
\end{tabular}

\section{Table 10}

A comparison of the alternative 3PLs with respect to risk

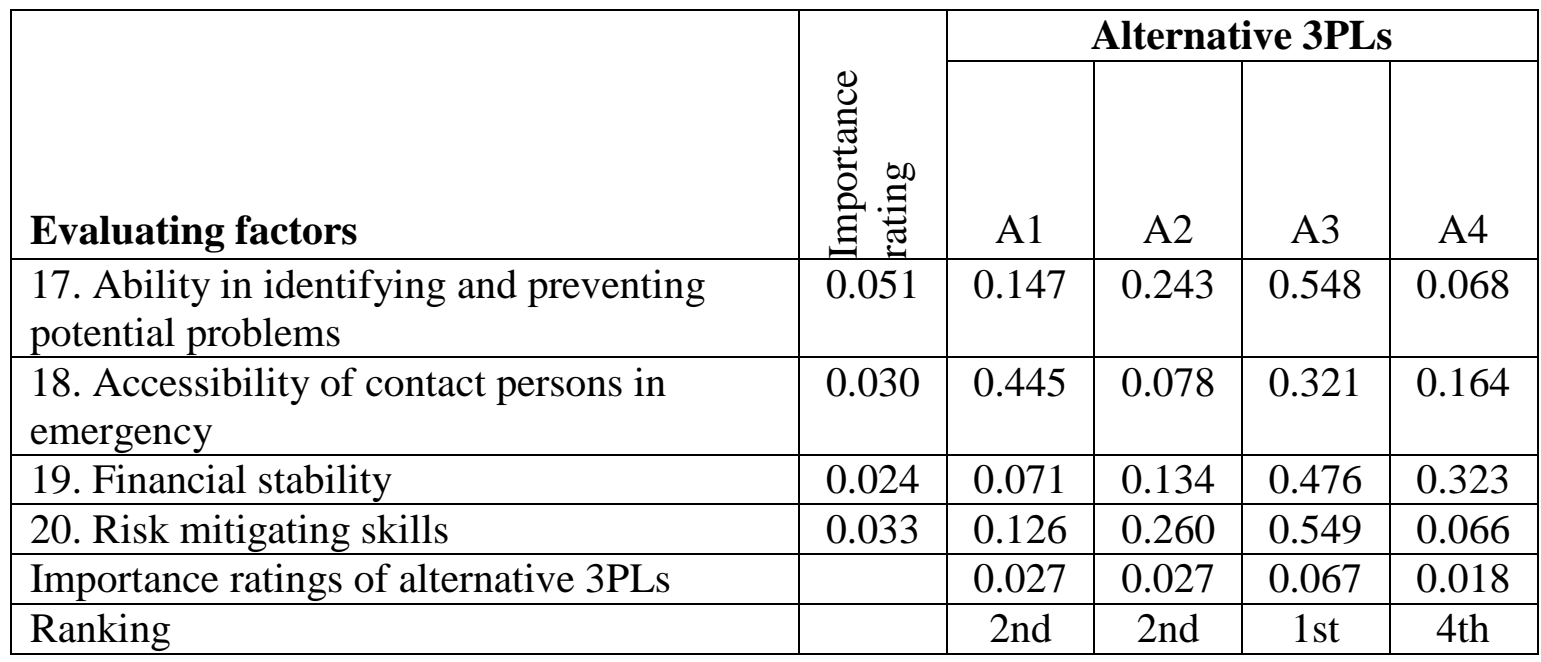




\section{University Library}

\section{- M M I N E R VA A gateway to Melbourne's research publications}

Minerva Access is the Institutional Repository of The University of Melbourne

Author/s:

Ho, W;He, T;Lee, CKM;Emrouznejad, A

Title:

Strategic logistics outsourcing: An integrated QFD and fuzzy AHP approach

Date:

2012

Citation:

Ho, W., He, T., Lee, C. K. M. \& Emrouznejad, A. (2012). Strategic logistics outsourcing: An integrated QFD and fuzzy AHP approach. Expert Systems with Applications, 39 (12), pp.10841-10850. https://doi.org/10.1016/j.eswa.2012.03.009.

Persistent Link:

http://hdl.handle.net/11343/118661 